\title{
Genotype and task influence stinging response thresholds of honeybee (Apis mellifera L.) workers of African and European descent
}

\author{
Jose L. Uribe-Rubio ${ }^{1}$, Tatiana Petukhova ${ }^{2}$, Ernesto Guzman-Novoa ${ }^{3^{*}}$ \\ ${ }^{1}$ CENIDFA-INIFAP, Animal Physiology Research Center, Ajuchitlán, Mexico \\ ${ }^{2}$ Department of Statistics, University of Guelph, Guelph, Canada \\ ${ }^{3}$ School of Environmental Sciences, University of Guelph, Guelph, Canada; ${ }^{*}$ Corresponding Author: eguzman@uoguelph.ca
}

Received 10 April 2013; revised 23 May 2013; accepted 27 June 2013

Copyright (C) 2013 Jose L. Uribe-Rubio et al. This is an open access article distributed under the Creative Commons Attribution License, which permits unrestricted use, distribution, and reproduction in any medium, provided the original work is properly cited.

\begin{abstract}
The stinging response thresholds of individual European and Africanized worker honeybees (Apis mellifera L.) were analyzed. Workers of each genotype performing defense (guard and soldier bees) and non-defense (nest and forager bees) associated tasks were collected and exposed to an electric stimulus of $0.5 \mathrm{~mA}$, and the time they took to sting a leather substrate was recorded. Africanized bees had significant lower thresholds of response than European bees. Guards and soldiers were faster to sting than nest and forager bees for the Africanized genotype, whereas for the European genotype, guards stung significantly faster than bees of the other three task groups. This is the first study that shows that individual bees specialized in two defensive tasks also have a lower response threshold for stinging. Our results fit a model of division of labor based on differences in response thresholds to stimuli among workers of different genotypes and task groups.
\end{abstract}

Keywords: Apis mellifera; Africanized Honeybees; Genotypic Effects; Defensive Behavior; Response Thresholds; Division of Labor

\section{INTRODUCTION}

Division of labor in insect societies can be explained by behavioral threshold variance among individual members of a colony [1,2]. In this model, it is assumed that individuals respond to stimuli on the basis of their response thresholds. Members with similar sets of thresholds will tend to perform similar tasks and thus end up in the same behavioral roles. Defensive behavior is an example of a highly advantageous behavior for the evolutionary and ecological success of honeybees [3]. Defensive tasks are carried out by guards and soldiers, individuals that specialize in either guarding the colony entrance or in stinging potential intruders [4]. Guards are middle-age bees (one to three weeks old) that patrol the entrance of their colony and inspect incoming individuals to identify them as nest mates or non-nest mates. Guards exclude bees (or other invertebrates) that are foreign to their colony, and alert other colony workers about intruders. By releasing pheromones, they recruit bees from the interior of the colony and some of the recruited bees (the soldiers) fly out, detect, pursue and sting vertebrate intruders [5].

Numerous studies have demonstrated that guarding and stinging are specialized tasks that are performed by few, genetically predisposed individuals [3] and loci associated with guarding and stinging behavior have been mapped and confirmed [6-9]. Thus, it is clear that guards and soldiers play an important role in colony defense. Genotypic effects on the defensive behavior of honeybees are also evident in nature. Africanized bees are an example of a defensive genotype; they are significantly more defensive than European bees [10-12]. There are other groups of bees that do not perform defensive tasks in honey bee colonies, but that specialize in nest-associated tasks such as cleaning cells, feeding larvae, tending the queen, and building comb. Foraging is also another non-defensive task performed typically by older individuals [13].

Individual tests are important to study the defensive behavior of honeybees because group measures may be subject to nonlinear effects owing to interactions among workers inside colonies. Electric stimulation assays reliably detect variability between genotypes for defensive 
response thresholds using individual honeybees as has been repeatedly demonstrated in previous studies [14-17], but very few studies have demonstrated genotype by task interactions for behavioral traits of honeybees. In the case of defensive behavior, it is not known how much the thresholds of response of individual bees are affected by specialized tasks. A recent study demonstrated that guard bees of Africanized colonies have a lower threshold of response to electrical stimulation than bees performing nest tasks [17], but such evaluations have never been conducted to compare bees performing other defensive and non-defensive tasks, which is critical to further strengthen the notion that response thresholds to defense stimuli are influenced by both genotype and behavioral tasks performed by individuals.

Here we report results of stinging response-thresholds to electric stimulation of two non-defensive groups of young and old workers (nest and forager bees) and two defensive groups of middle age and presumably older workers (guard and soldier bees) taken from European and Africanized honeybee colonies.

\section{MATERIALS AND METHODS}

\subsection{Study Area and Genotypes}

This study was conducted at Mexico's Animal Physiology Research Center in Ajuchiltlan, Queretaro, Mexico $\left(21^{\circ} \mathrm{N}, 22^{\circ} \mathrm{W}\right)$. Experimental honeybees were obtained from five Africanized and five European bee colonies. The Africanized colonies were derived from queens of swarms captured locally. The European colonies were derived from queens of Carniolan descent that were previously imported from Ontario, Canada. Morphometric and mitochondrial DNA analyses [18] of the queens' progeny confirmed the origin of the source colonies.

\subsection{Bioassay and Data Collection}

The stinging response thresholds to an electric stimulus of bees performing two distinct defensive tasks [4] and two distinct non-defensive tasks (nest and forager bees) [13] were determined. To collect bees of the above behavioral categories from the source colonies, different procedures were followed. Nest bees were individually captured from brood combs in the interior of the colonies by gently placing an inverted 15 -ml plastic tube over the bee on the comb, whereas bees performing guarding bouts were captured at the hives' entrances. Guard bees were detected by observing their "typical" behavior [4] for a period of $5 \mathrm{~min}$ before taking the sample. Guard bees stand with their forelegs off the ground and their antennae held forwards to touch and inspect incoming bees. Once identified, guards were captured by gently placing a plastic tube over the bee on the landing board of the hive. To capture foragers, a wire mesh was used to blockade the hive entrance, which forced returning fora-gers to land on it. Foragers were identified as bees returning to the hive with pollen loads and were collected following the same procedure used to capture guard bees. Soldiers were collected as previously described [19]. Briefly, a pyramidal-shaped net trap was made to fit the dimensions of the hive with four triangular pieces of white wood (two $55.5 \times 90 \mathrm{~cm}$ and two $45.5 \times 90 \mathrm{~cm}$ ) that were covered with mosquito net. A flag $(10 \times 8 \mathrm{~cm}$ black paper patch attached to a $100 \mathrm{~cm}$ long wooden stick) was inserted through the tip of the net. Each experimental colony was opened and the triangular net placed on top of the hive, trying not to disturb the bees. Then a flag was presented ca. $10 \mathrm{~cm}$ above the top of the combs in the brood chamber. The flag was moved in zigzag manner across all frames at a rate of 1 circuit/s for 20 $\mathrm{s}$ to present a quick stimulus to attract the most sensitive bees to try to sting the paper. The trap was withdrawn and closed to prevent the soldiers inside it from escaping and was immediately transported to the laboratory. In the laboratory, bees were individually transferred from the trap into plastic containers as above. Bees of all task groups contained in tubes were tested within $1 \mathrm{~h}$ after collection. A total of 125 bees per task group were tested for each genotype, and all colonies were equally represented.

A constant-current stimulator (Isostim 360, model A 320 R-E, World Precision Instruments, Sarasota, Fla., USA) was used to provide a constant stimulus regardless of variation in resistance caused by the manner a bee touched the wires, or the size of the bee. A fixed electric stimulus of $0.5 \mathrm{~mA}$ was applied, with a pulse interval of $250 \mathrm{~ms}$ and an amplitude of $2.0 \mathrm{~ms}$. These conditions were set based on previous studies that tested the effects of varying pulse rate, interval, voltage or current to induce stinging. A constant current of $0.5 \mathrm{~mA}$ showed good separation between European and Africanized workers captured at the hive entrance [17]. The electric stimulator was connected to a wire grid composed of parallel stainless steel wires $(13 \mathrm{~cm} \times 2 \mathrm{~mm})$ with a separation of $3.5 \mathrm{~mm}$ between them [15]. The grid wires were assembled in an alternate electric manner (+ and -$)$ so that the circuit was closed by the bee touching two adjacent wires.

Individual bees were placed unrestrained above the device's grid with the aid of entomological forceps. Then, the individual was covered with an inverted plastic Petri dish $(57 \mathrm{~mm}$ diameter) that restrained the bee within the grid, but allowed her to freely walk on it. Then, the bee was left undisturbed for $5 \mathrm{~min}$ to allow her to acclimate before being stimulated. Each bee was then subjected to the electric stimulation and the time taken by the individual from the application of the electric stimulus to the stinging of a black suede leather patch placed underneath the wire grid, was measured with a precision chronome- 
ter (Leonidas trackmaster, model 8042, Bern, Switzerland). The black suede was used to provide a more realistic target to sting. Defenders localize potential intruders in the field by visual cues and odor and are more responsive to dark colored objects with a mammalian smell [3]. A new suede patch was used for each bee and the wire grid was cleaned with a solution of water and neutral soap after each test to remove possible residues of alarm pheromones left by the previous bee.

\subsection{Statistical Analysis}

The data did not show a normal distribution based on histogram visual assessments; thus, they were subjected to the Box-Cox method to power-transform them and stabilize the variance. A linear mixed effects model was used to analyze colony and task effects on time to sting within each genotype because colonies are nested within genotype groups and as such are not independent. Since colony effects were not significant after this initial analysis, the data of both genotypes were combined and subjected to factorial analyses of variance to detect genotype and genotype $\mathrm{x}$ task interaction effects. When significant differences were found, means were compared with Tukey tests.

\section{RESULTS}

Time to sting was not significantly affected by colony effects neither for European bees $\left(F_{4,495}=1.27, P=\right.$ $0.283)$, nor for Africanized bees $\left(F_{4,495}=2.02, P=0.090\right)$. However, Africanized bees responded significantly faster to the electric stimulus than European bees $\left(F_{1,998}=\right.$ $108.15, P<0.0001)$ with mean stinging times of $2.32 \pm$ 0.15 and $3.06 \pm 0.18 \mathrm{~s}$, respectively. Africanized bees performing both defense activities (guards and soldiers) stung significantly faster than bees not performing defense tasks (nest and forager bees) $\left(F_{3,496}=70.81, P<\right.$ 0.0001 ; Figure 1), but in European bees, no differences were detected for time to sting among three task groups (nest, forager and soldier bees), although guards stung significantly faster than forager and nest bees $\left(F_{3,496}=\right.$ 5.92, $P<0.001$; Figure 2). Additionally, interaction effects between genotype and task were evident $\left(F_{3,992}=\right.$ 27.42, $P<0.0001$ ), with Africanized bees being faster responders specifically for the defense associated tasks.

\section{DISCUSSION}

Africanized bees responded faster than Europeans to the electric stimulus used in this study. The genotypic effects reported here agree with studies that have shown that Africanized bees are more defensive than European bees [3]. These results also confirm those of a previous study showing that Africanized bees have a lower threshold of stinging response than European bees to

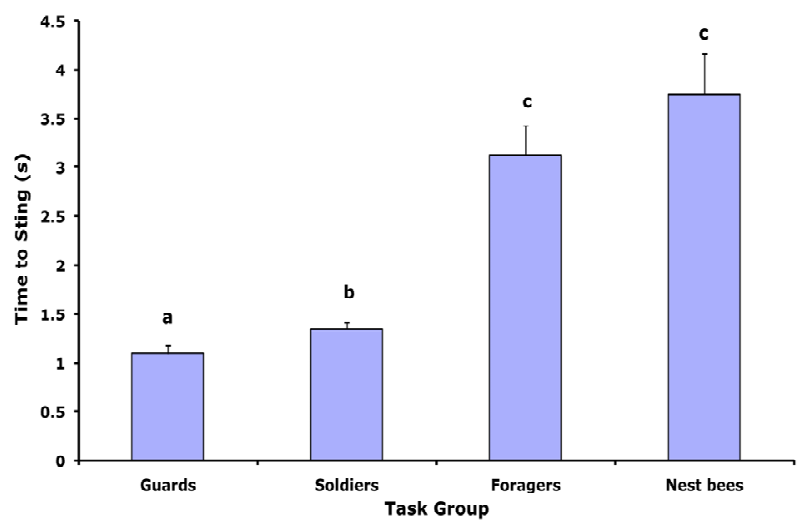

Figure 1. Effect of task on mean time to sting ( $\mathrm{s} \pm$ s.e.) for individual Africanized honeybees performing defensive tasks (guards and soldiers) and non-defensive tasks (nest and foragers). Worker bees $(n=500)$ collected from five colonies were subjected to a $0.5 \mathrm{~mA}$ electric stimulus and the time they took to sting a leather substrate was recorded. Different literals indicate significant differences of means, based on analysis of variance and Tukey tests of Box-Cox transformed-data. Actual nontransformed values are shown.

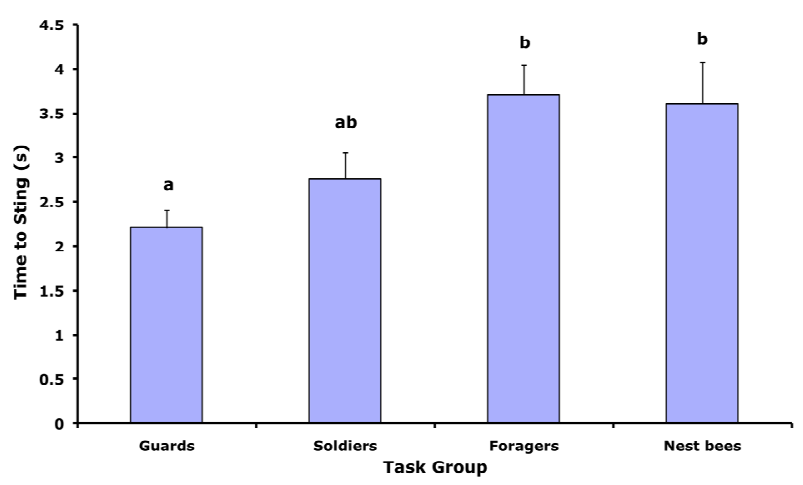

Figure 2. Effect of task on mean time to sting ( $\mathrm{s} \pm$ s.e.) for individual European honeybees performing defensive tasks (guards and soldiers) and non-defensive tasks (nest and foragers). Worker bees $(n=500)$ collected from five colonies were subjected to a $0.5 \mathrm{~mA}$ electric stimulus and the time they took to sting a leather substrate was recorded. Different literals indicate significant differences of means, based on analysis of variance and Tukey tests of Box-Cox transformed-data. Actual non-transformed values are shown.

electric stimulation [17] and support the validity and reliability of using an electric stimulator to study defensive responses and to test threshold models in honeybee studies. Additionally, results of this study provide further evidence of variability for stinging response thresholds depending on the task performed by the bees. Overall, bees performing defensive tasks responded faster than bees performing non-defensive tasks. This variability associated to defensive and non-defensive tasks was more evident in Africanized workers than in European workers, where only one task group (guards) showed significantly faster responses than the other three groups. This is the 
first time that evidence is generated showing that genotype and task specialization, rather than age, influence thresholds of stinging response in Africanized bees. Africanized bees specialized in defensive tasks performed by middle-age bees (guards) and by presumably older bees (soldiers), stung faster than bees specialized in nondefensive tasks performed by both, young (nest bees) and old workers (foragers). In European bees, young and old workers did not differ for time to sting. Therefore, our results do not support the idea that as bees get older, they are more prone to be defensive, unless they specialize in defensive tasks. This is particularly clear in Africanized bees.

Only one study has previously compared the stinging response to electric stimulation of Africanized and European bees [17], but this is the first time that two nondefensive and two defensive-associated tasks are evaluated in the two bee types. This study provides evidence indicating that individuals specialized in two different defense tasks, also have a lower response threshold for stinging, which supports the hypothesis that defensive bees may have lowered response thresholds to defensive stimuli [20].

Perhaps differences were found between Africanized bees performing defensive tasks and Africanized bees performing non-defensive tasks in the colonies of this study because the alleles of African origin may have a greater effect on the stimulus response threshold than the allelic variation within European bees. Additionally, the fact that Africanized bees are more persistent as guards than are European bees reinforces this argument [21]. The above speculations are in agreement with the evolutionary histories of African and European subspecies of honeybees, in which bees of African ancestry show a more evolved level of defense specialization than bees of European origin [22].

Our results indicate that genotype and task specialization influence the stinging response thresholds of honeybees, particularly in workers of African ancestry. The identification of these components associated with the variability in stinging behavior of individual honeybees is consistent with a response-threshold model that explains the division of labor in the colony as the result of variability for the sensitivity to various stimuli among its members $[1,2]$.

\section{ACKNOWLEDGEMENTS}

We thank Eusebio Pedroza for technical support and bee management received during the course of the experiments.

\section{REFERENCES}

[1] Robinson, G.E. (1992) Regulation of division of labor in insect societies. Annual Review of Entomology, 37, 637665. doi:10.1146/annurev.en.37.010192.003225
[2] Page, R.E. and Erber, J. (2002) Levels of behavioral organization and the evolution of division of labor. Naturwissenschaften, 89, 91-106. doi:10.1007/s00114-002-0299-x

[3] Breed, M.D., Guzmán-Novoa, E. and Hunt, G.J. (2004) Defensive behavior of honey bees: Organization, genetics, and comparisons with other bees. Annual Review of Entomology, 49, 271-298. doi:10.1146/annurev.ento.49.061802.123155

[4] Breed, M.D., Robinson, G.E. and Page, R.E. (1990) Division of labor during honey bee colony defense. Behavioural Ecology and Sociobiology, 27, 395-401. doi:10.1007/BF00164065

[5] Guzmán-Novoa, E., Hunt, G.J., Uribe-Rubio, J.L. and Prieto-Merlos, D. (2004) Genotypic effects of honey bee (Apis mellifera) defensive behavior at the individual and colony levels: The relationship of guarding, pursuing and stinging. Apidologie, 35, 15-24. doi:10.1051/apido:2003061

[6] Hunt, G.J., Guzmán-Novoa, E., Fondrk, M.K. and Page, R.E. (1998) Quantitative trait loci for honeybee stinging behavior and body size. Genetics, 148, 1203-1213.

[7] Guzmán-Novoa, E., Hunt, G.J., Uribe-Rubio, J.L., Smith, C. and Arechavaleta-Velasco, M.E. (2002) Confirmation of QTL effects and evidence of genetic dominance of honeybee defensive behavior: Results of colony and individual behavioral assays. Behavioral Genetics, 32, 95102. doi:10.1023/A:1015245605670

[8] Arechavaleta-Velasco, M.E., Hunt, G.J. and Emore, C. (2003) Quantitative trait loci that influence the expression of guarding and stinging behaviors of individual honey bees. Behavioral Genetics, 33, 357-364. doi:10.1023/A:1023458827643

[9] Arechavaleta-Velasco, M.E. and Hunt, G.J. (2004) Binary trait loci that influence honey bee guarding behavior. Annals of the Entomological Society of America, 97, 177183. doi:10.1023/A:1023458827643

[10] Collins, A.M., Rinderer, T.E., Harbo, J.R. and Bolten, A.B. (1982) Colony defense by Africanized and European honeybees. Science, 218, 72-74. doi:10.1126/science.218.4567.72

[11] Guzmán-Novoa, E. and Page, R.E. (1994) Genetic dominance and worker interactions affect honeybee colony defense. Behavioral Ecology, 5, 91-97. doi:10.1093/beheco/5.1.91

[12] Uribe-Rubio, J.L., Guzmán-Novoa, E., Hunt, G.J., CorreaBenitez, A. and Zozaya, R.J.A. (2003) Effect of Africanization on honey production, defensive behavior and size in honey bees (Apis mellifera L.) of the Mexican high plateau. Veterinaria Mexico, 34, 47-59.

[13] Winston, M.L. (1987) The biology of the Honeybee. Harvard University Press, Cambridge.

[14] Kolmes, S.A. and Fergusson-Kolmes, L.A. (1989) Measurements of stinging behaviour in individual worker honeybees (Apis mellifera L.). Journal of Apicultural Research, 28, 71-78.

[15] Paxton, R.J., Sakamoto, C.H. and Rugiga, F.C.N. (1994) Modification of honey bee (Apis mellifera L.) stinging behaviour by within-colony environment and age. Journal of Apicultural Research, 33, 75-82. 
[16] Lenoir, J.C., Laloi, D., Dechaume-Moncharmont, F.X., Solignac, M. and Pham, M.H. (2006) Intra-colonial variation of the sting extension response in the honey bee Apis mellifera. Insectes Sociaux, 53, 80-85. doi:10.1007/s00040-005-0838-5

[17] Uribe-Rubio, J.L., Guzmán-Novoa, E., Vázquez-Peláez, C. and Hunt, G.J. (2008) Genotype, task specialization, and nest environment influence the stinging response thresholds of individual Africanized and European honeybees to electrical stimulation. Behavioral Genetics, 38, 93-100. doi:10.1007/s10519-007-9177-9

[18] Nielsen, D.I., Ebert, P.R., Hunt, G.J., Guzmán-Novoa, E., Kinnee, S.A. and Page, R.E. (1999) Identification of Africanized honey bees (hymenoptera: Apidae) incorporating morphometrics and an improved PCR mitotyping procedure. Annals of the Entomological Society of America, 92, 167-174.

[19] Alaux, C., Sinha, S., Hasadsri, L., Hunt, G.J., Guzman-
Novoa, E., DeGrandi-Hoffman, G., Uribe-Rubio, J.L., Southey, B.R., Rodriguez-Zas, S. and Robinson, G.E. (2009) Honey bee aggression supports a link between gene regulation and behavioral evolution. Proceedings of the National Academy of Sciences USA, 106, 1540015405. doi:10.1073/pnas.0907043106

[20] Robinson, G.E. and Page, R.E. (1988) Genetic determination of guarding and undertaking in honey-bee colonies. Nature, 333, 356-358. doi:10.1038/333356a0

[21] Hunt, G.J., Guzmán-Novoa, E., Uribe-Rubio, J.L. and Prieto-Merlos, D. (2003) Genotype by environment interactions in honey bee guarding behavior. Animal Behavior, 66, 469-477. doi:10.1006/anbe.2003.2253

[22] Guzman-Novoa, E., Correa-Benítez, A., Guzmán, G. and Espinoza-Montaño, L.G. (2011) Colonization, impact and control of Africanized honey bees in Mexico. Veterinaria Mexico, 42, 149-178. 